\title{
Subareolar Region
}

National Cancer Institute

\section{Source}

National Cancer Institute. Subareolar Region. NCI Thesaurus. Code C62225.

The area of the chest beneath the areola of the nipple. 